\title{
Elderly High-Risk Stage II Colorectal Cancer Patients: Candidates for Improving Outcome?
}

\author{
Min Ki Kim \\ Department of Surgery, Myongi Hospital, Hanyang University College of Medicine, Goyang, Korea
}

\section{See Articles on Page 298-305}

In stage II colorectal cancer, there are many interesting subthemes, especially since there are many factors that can affect the prognosis and the benefits of chemotherapy have not been clearly concluded. For example, does the prognosis become worse as there are more high-risk features? Does chemotherapy affect the prognosis differently depending on the presence or number of high-risk features? Does the addition of oxaliplatin to the chemotherapy regimen make a difference in the prognosis? How long is the ideal chemotherapy period? And whether chemotherapy is beneficial in the elderly.

Lee et al. [1] deal with the last topic. They compared the results of the group that completed more than $80 \%$ of scheduled adjuvant chemotherapy for patients with high-risk features among patients aged 70 years or older with stage II colorectal cancer and those who did not.

Although there was no difference in long-term outcomes between the 2 groups, chemotherapy was found to be the only favorable factor for relapse-free survival in the 3 or more risk-having groups. In a study with a small number of samples, it is better to pay attention to the implications of a positive finding rather than a negative one. We previously analyzed the Korean national data and announced that the more high-risk features there are, the worse the overall survival tends to be, and chemotherapy offsets this tendency [2].

In that study, the rate of adjuvant chemotherapy for stage II

Received: Oct 1, 2021 - Accepted: Oct 5, 2021

Correspondence to: Min Ki Kim, M.D., Ph.D.

Department of Surgery, Myongji Hospital, Hanyang University College of Medicine, 55 Hwasu-ro 14beon-gil, Deogyang-gu, Goyang 10475, Korea

Tel: +82-31-810-5441, Fax: +82-31-969-0500

E-mail: arrokim@gmail.com

ORCID: https://orcid.org/0000-0002-9560-0775

(C) 2021 The Korean Society of Coloproctology

This is an open-access article distributed under the terms of the Creative Commons Attribution NonCommercial License (https://creativecommons.org/licenses/by-nc/4.0) which permits unrestricted noncommercial use, distribution, and reproduction in any medium, provided the original work is properly cited. high-risk group patients was $59.4 \%$, whereas in a registry study published in the United Kingdom in 2017, only $24 \%$ of 1,175 patients with high-risk stage II ( $16 \%$ for those aged 70 years or older) were treated with adjuvant chemotherapy [3]. Despite the conflicting evidence, the large difference in treatment rates between the 2 social groups means that active discussion and research on the subject of this thesis is necessary.

About $60 \%$ of newly diagnosed colorectal cancer patients are over 70 years of age [4], with the global aging population and advances in medicine and economy, the number of these elderly patients will increase further. This could facilitate research to select patients who would benefit from adjuvant chemotherapy in colorectal cancer with severe heterogeneity in survival and recurrence. In addition, recent advances in precision medicine [5] may also assist in such patient selection.

It is expected that treatment to obtain survival gains through adjuvant chemotherapy for carefully selected elderly colorectal patients with a high risk of recurrence and low risk of side effects, with an optimal regimen and duration will become one of the new-normals.

\section{CONFLICT OF INTEREST}

No potential conflict of interest relevant to this article was reported.

\section{REFERENCES}

1. Lee Y, Park I, Cho H, Gwak G, Yang K, Bae BN. Effect of adjuvant chemotherapy on elderly stage II high-risk colorectal cancer patients. Ann Coloproctol 2021;37:298-305.

2. Kim MK, Won DD, Park SM, Kim T, Kim SR, Oh ST, et al. Effect of adjuvant chemotherapy on stage II colon cancer: analysis of Korean national data. Cancer Res Treat 2018;50:1149-63.

3. Booth CM, Nanji S, Wei X, Peng Y, Biagi JJ, Hanna TP, et al. Adjuvant chemotherapy for stage II colon cancer: practice patterns and effectiveness in the general population. Clin Oncol (R Coll Radiol) 2017;29:e29-38.

4. Chong RC, Ong MW, Tan KY. Managing elderly with colorectal 


\section{Coloproctology Min Ki Kim}

cancer. J Gastrointest Oncol 2019;10:1266-73.

5. Yang L, Chen P, Zhang L, Wang L, Sun T, Zhou L, et al. Prognostic value of nucleotyping, DNA ploidy and stroma in high-risk stage II colon cancer. Br J Cancer 2020;123:973-81. 